\title{
Acute inpatient psychiatry in England: an old problem and a new priority
}

\author{
PAUL LELLIOTT
}

\begin{abstract}
With the development of community care, the number of National Health Service psychiatric beds in England has been reduced to between one-fifth and one-quarter of those provided in the mid-1950s. Psychiatric bed numbers are close to the irreducible minimum if they have not already reached it. The problems facing today's acute psychiatric admission wards include: poor design, maintenance and ambience; a lack of therapeutic and leisure activities for patients leading to inactivity and boredom; frequent incidents of aggression and low-level violence and problems with staffing. It is suggested that there are a number of underlying causes: First, there has been failure to plan inpatient services, or to define their role, as attention has focused on new developments in community care. Second, the reduction in bed numbers has led to a change in the casemix of inpatients with a concentration on admission wards of a more challenging group of patients. Third, admission ward environments are permeable to the adverse effects of local street life, including drug taking. After years of neglect, acute inpatient psychiatric services in England are now high on the UK Government agenda. The paper lists a number of national initiatives designed to improve their quality and safety. A recent review of qualitative research suggests that acute psychiatric wards in other countries face similar problems to those reported in England. It is suggested that there might be a need for joint action which might take the form either of international research about acute inpatient care or the development of international standards and a common quality improvement system.
\end{abstract}

\section{FIFTY YEARS OF CHANGE FOR PSYCHIATRIC INPATIENT SERVICES IN ENGLAND}

As in other developed, Western Countries, the locus of mental health care in England has shifted progressively over the past 50 years (Lamb \& Bachrach, 2001). Before the 1960 s, services were located predominantly in large psychiatric hospitals that were often geographically remote from the population they served. At that time, the Government decided that the large psychiatric hospitals would be phased out and replaced by psychiatric services organized around admission beds in district general hospitals; located in the catchment area of the population served. The reasons were a complex mix of the political, moral and economic. This reform was justified by research about the adverse effects of institutionalism and partly enabled by the introduction of effective antipsychotic drugs.

Address for correspondence: Dr. P. Lelliott, Director, Royal College of Psychiatrists' Research and Training Unit, 4th Floor, Standon House, 21 Mansell Street, London EI 8AA (United Kingdom).

Fax: +44-020-7481.4831

E-mail: plelliott@cru.rcpsych.ac.uk

Declaration of Interest: The Royal College of Psychiatrists' Research and Training Unit has received grants to conduct research about inpatient care and to conduct the national Audit of Violence on behalf of the Healthcare Commission. It also manages the Accreditation for acute Inpatient Mental Health Services Initiative (AIMS).
In the early 1980s, English mental health care entered a third stage with the gradual development of more comprehensive community services that came to be dispersed across community mental health centres; many of which were located in residential areas. The preferred locus of psychiatric care became the patient's own home. This was formalized in the Government's NHS Plan, which set targets for the introduction of crisis resolution and home treatment teams, as an alternative to inpatient care (HMSO, 2000). The accompanying National Service Framework for Mental Health stated that, were admission needed, it should be "in the least restrictive environment consistent with the need to protect them and the public ....[and]... as close to home as possible" (Department of Health, 1999).

Consistent with these changes, the number of psychiatric beds provided by the National Health Service in England has been reduced to between one-fifth and onequarter of those provided in the mid-1950s. However, the rate of reduction has lessened over the past five year and there is growing recognition that psychiatric bed numbers in England are close to the irreducible minimum (Mental Health Act Commission, 2005).

\section{PROBLEMS FOR PSYCHIATRIC ADMISSION WARDS IN ENGLAND}

These have been well documented over the past 15 years and confirmed as still present by recent national surveys and reviews (Healthcare Commission, 2005; 
Marshall et al., 2004; Mental Health Act Commission, 2005; Sainsbury Centre for Mental Health, 2005). The design and layout of many acute psychiatric wards are unsuited to the provision of care that is both safe and which respects the privacy and dignity of patients. Some wards are dirty, in need of redecoration and refurbishment, have inadequate heating, ventilation or air conditioning and limited access to outdoor space. For patients, life on the ward can be characterized by inactivity and boredom; wards may provide few therapeutic or leisure activities, especially in the evening and at weekends. At the same time, wards can be unsafe places with frequent incidents of aggression and low level violence, of self-harm and of patients leaving the ward without the agreement of staff (see table I). There are often problems with the staffing of admission wards; with few experienced nurses on each shift and extensive use of "agency" and "bank", staff; that is nurses who are brought in to work shifts on the ward but who are not employed by the mental health service and so who often do not know the ward or the patients.

Table I. - Relative frequency of patient safety incidents on acute psychiatric wards in England and Wales (taken from Marshall et al., 2004).

\begin{tabular}{llll}
\hline & $\begin{array}{l}\text { Number of incidents each } \\
\text { years in England and Wales }\end{array}$ & $\begin{array}{l}\text { Number of admissions } \\
\text { per incident }\end{array}$ & $\begin{array}{l}\text { Interval between incidents } \\
\text { for an average ward }\end{array}$ \\
\hline Aggression/minor assaults & 300,000 & 0.5 & 1 day \\
Absconding & 50,000 & 3 & 6 days \\
Sexual harassment/assault & 45,000 & 4 & 1 week \\
Self-harm & 25,000 & 6 & 12 days \\
Absconding - does not return & 4,500 & 35 & 10 weeks \\
Death by suicide & 200 & 800 & 4 years \\
Unnatural death of detained patients & 85 & 1,800 & 9 years \\
Homicide by in-patient & 1.3 & 115,000 & 600 years \\
\hline
\end{tabular}

Unsurprisingly, service user surveys and testimony suggest that many patients in England are dissatisfied with their experience of psychiatric hospitalization (Rethink, 2004; Rose, 2000) and one commentator has branded acute inpatient care as atherapeutic (Muijen, 1999).

The likely underlying causes of the problems are interrelated. They can be summarized as follows:

\section{- Inpatient services are a neglected part of the men-} tal healthcare system in England. Inpatient provision has not been planned systematically, in the way that has happened with non-hospital care. Rather, it has developed ad-hoc, or as an afterthought as policy and managerial attention has focused on the establishment of new community services (Mental Health Act Commission, 2005; Sainsbury Centre for Mental Health, 2005). The latter have greater prestige and offer a better career development path for ambitious nurses than does acute ward psychiatry. Historically, this neglect extends to research. Compared with new forms of community services, such as assertive outreach, crisis resolution and home treatment, there have been very few evaluations of the effectiveness of acute inpatient care; indeed hospital admission is usually part of the package of "standard" care against which these new community services are compared.

- The role of acute inpatient care is ill-defined. Most admissions are unplanned and happen at a time of crisis. Admission is in effect a default option when care in the community has failed; rather than an active and purposeful care intervention. The decision to admit is not under the control of ward staff. The trigger for admission is usually risk posed by the patient, to self or others. As a result, the purpose of inpatient care is usually containment and risk management; rather than active therapy.

- Admission wards are "permeable" environments. Today's admission wards are very different from the long-stay psychiatric wards of the old asylum. The latter were closed institutions; cut off, geographically and socially from the outside world (Goffman, 1961). In contrast, acute wards are "permeable" institutions (Quirk et al., in press). They are impermanent, with short stays for patients and high staff turnover. Institutional identities are blurred, with staff and patients dressed alike and relationships between them characterized by informality. Patients and staff maintain a high level of contact and communication with the outside world. Although permeability has positive consequences, in that it can reduce the risk of institutionalism and ease the patient's reintegration back into the community, it can also cause problems. Staff have difficulty in regulating movement onto and off the ward and the ward culture can become imbued with the problems of local street life including criminality and substance misuse. 
- Bed closures have preceded developments in community care and have been driven by over-optimistic estimates of the impact of new community services on the need for hospitalization (King's Fund, 2003). This has resulted in high occupancy rates (MILMIS Project Group, 1995; Mental Health Act Commission, 2005) and the apparently paradoxical situation that, as bed numbers have fallen, so rates of admission have risen. This is due to rapid turnover and resulting shorter lengths of stay as patients are discharged early to make way for new admissions. Inevitably a significant proportion of patients are readmitted shortly after discharge. At the other extreme, the long-stay hospital closure programme did not adequately take account of the fact that people would continue to present to services whose disability was so severe, or who posed such risk, that they would require longer term hospital care. Although the rate of recruitment of such patients is low in absolute terms, over time, and given the very low numbers of rehabilitation or longstay beds to which they can be moved, it poses a significant challenge to admission wards. People who are difficult to discharge both block beds and create challenges for staff teams and ward regimes that are not designed to meet the needs of such patients (Lelliott \& Wing, 1994).

- The casemix of admission wards has changed. In most English mental health services, the ward to which a person of working age is admitted is determined solely by geography. Wards therefore usually contain a mix of younger and older people, people who are detained under mental health legislation and those admitted informally, people with and without problems of substance misuse, people who pose a risk to themselves and those who are a risk to others, and people with a wide range of diagnoses. Overall, the severity of the problems of acute inpatients has increased over the past 10 or 20 years. This is partly due to the fact that a raising of the threshold for admission has led to a concentration on acute wards of those deemed to be at higher risk. A higher proportion of inpatients today are young men and compulsorily detained under the Mental Health (Fitzpatrick et al., 2003; Lelliott, 1996). Also, a high proportion of those admitted have comorbid drug and alcohol problems (Fitzpatrick et al., 2003; Phillips \& Johnson, 2003). This is partly a reflection of a growing problem of substance misuse and also because the combination of mental illness and substance misuse is associated with the type of risk behaviours that influence decisions to admit.

\section{ACUTE INPATIENT CARE AS A NATIONAL PRIORITY}

After years of neglect, acute inpatient psychiatric services in England are now high on the UK Government agenda and some new investment has been made; both in upgrading psychiatric wards and in undertaking new research. The English Department of Health has recently issued new policy guidance about this aspect of mental health services and has established local "acute care forums" to oversee local policy implementation (Department of Health, 2002). Also, Government agencies responsible for setting standards for and regulating English health services have made acute inpatient care a priority. The emphasis of several of these initiatives has been on improving the safety of admission wards. However, all highlight the close relationship between safety and the quality both of care and of the ward environment.

The National Institute for Health and Clinical Excellence (NICE) has published evidence-based clinical practice guidelines about the management of disturbed behaviour in inpatient mental health settings (NICE, 2005). The Healthcare Commission (the regulatory body for English health services) has recently completed a national audit of violence in psychiatric inpatient units which makes recommendations about how to improve both ward safety and quality of care (Healthcare Commission, 2005). The Healthcare Commission also plans to undertake a national thematic review of the quality of psychiatric inpatient care in 2006. The National Patient Safety Agency has chosen safer wards for acute psychiatry as its first priority in mental health (Marshall et al., 2004).

\section{AN ACCREDITATION SYSTEM FOR ACUTE PSYCHIATRIC WARDS}

The Royal College of Psychiatrists (the professional body for psychiatrists in the United Kingdom and Ireland) is working, through its Research and Training Unit, to develop an accreditation system for acute admission wards. Accreditation will be underpinned by a comprehensive set of service standards (Royal College of Psychiatrists Research and Training Unit, 2006) that will be applied through a process involving both self-review, by staff working on the ward concerned, and peer-review during a visit by staff from other psychiatric units that are engaged in the accreditation process. The hope is that this systematic approach to quality monitoring, combined with the benefits of participation in a national network of acute inpatient services, will lead to incremental 
improvements in quality. The system will be modeled on that used to accredit electroconvulsive therapy clinics (Caird et al., 2004).

\section{INTERNATIONAL PERSPECTIVE}

A review of recent qualitative research concluded that acute psychiatric wards in other countries face similar problems to those reported in England (Lelliott \& Quirk, 2004). One common theme was a preoccupation with the management of dangerous behaviour and high patient throughput. Another was dissatisfaction, among both staff and patients, about the difficulty of creating therapeutic relationships in this environment and about the over-emphasis of pharmacological interventions at the expense of psychological therapies.

If there is such a common agenda, is there the need for joint action? This might be take the form either of international research about acute inpatient care or the development of international standards and a common quality improvement system. The agenda for such a programme of research and development might include: the better definition of the role of acute wards in a modern mental health service and of the specialty of inpatient psychiatry; the identification of the interventions that admission wards should be delivering and delineation of the factors that lead to a better experience for patients.

\section{REFERENCES}

Caird H., Worrall A. \& Lelliott P. (2004). The Electroconvulsive Therapy Accreditation Service (ECTAS). Psychiatric Bulletin 28, 257-259.

Department of Health (1999). National Service Framework for Mental Health: Modern Standards and Service Models. Department of Health: London. Retrieved February 23, 2006, from http://www.dh. gov.uk/assetRoot/04/07/72/09/04077209.pdf

Department of Health (2002). Mental Health Policy Implementation Guide: Adult Acute Inpatient Care Provision. Department of Health: London. Retrieved February 23, 2006, from http://www.dh.gov.uk/ PublicationsAndStatistics/Publications/PublicationsPolicyAndGuid ance/PublicationsPolicyAndGuidanceArticle/fs/en?CONTENT_ID $=4009156 \& \mathrm{chk}=\mathrm{hdBfGn}$.

Fitzpatrick N.K., Thomson C.J., Hemingway T.R.E., Barnes A., Higgitt, A., Molloy C. \& Hargreaves S. (2003). Acute mental health admissions in inner London: changes in patient characteristics and clinical admission thresholds between 1988 and 1998. Psychiatric Bulletin 27, 7-11.

Goffman E. (1961). Asylums. Penguin: London.

Healthcare Commission (2005). National Audit of Violence (20032005). Healthcare Commission:London. Retrieved February 23, 2006, from http://www.healthcarecommission.org.uk/assetRoot/ 04/01/74/51/04017451.pdf

HMSO (2000). The NHS Plan: a Plan for Investment a Plan for Reform. HMSO:London. Retrieved February 23, 2006, from http://www.dh. gov.uk/assetRoot/04/05/57/83/04055783.pdf

King's Fund (2003). London's State of Mind: King's Fund Mental Health Inquiry 2003. King's Fund: London.

Lamb H.R. \& Bachrach L.L. (2001). Some perspectives on deinstitutionalization. Psychiatric Services 52, 1039-1045.

Lelliott P. (1996). Meeting the accommodation needs of the most severely mentally ill people. Journal of Interprofessional Care 10, 241-247.

Lelliott P. \& Quirk A. (2004). What is life like on acute psychiatric wards? Current Opinion in Psychiatry 17, 297-301.

Lelliott, P. \& Wing, J.K. (1994). National audit of new long-stay psychiatric patients. II. Impact on services. British Journal of Psychiatry 165, 170-178.

Marshall H., Lelliott P. \& Hill K. (2004). National Patient Safety Agency Safer Wards for Acute Psychiatry: a Review of the Available Evidence. National Patient Safety Agency: London. Retrieved February 23, 2006, from http://www.npsa.nhs.uk/site/media/documents/1241_SWAP_ResearchReport.pdf

Mental Health Act Commission (2005). In Place of Fear: $11^{\text {th }}$ Biennial Report 2003-2005. The Stationery Office:London. Retrieved February 23, 2006, from http://www.mhac.org.uk/Pages/documents/publications/MHAC\%2011\%20TEXT\%20FA.pdf

MILMIS Project Group (1995). Monitoring inner London mental illness services. Psychiatric Bulletin 23, 257-259.

Muijen M. (1999). Acute hospital care: inefficient, ineffective and poorly organized. Editorial. Psychiatric Bulletin 23, 257-259.

NICE (2005). Violence - The short-term management of disturbed/violent behaviour in in-patient psychiatric settings and emergency departments. National Institute for Health and Clinical Excellence: London. Retrieved February 23, 2006, from http://www.nice.org.uk/ page. aspx $?=244477$.

Phillips P. \& Johnson S. (2003). Drug and alcohol misuse among inpatients with psychotic illnesses in three inner-London psychiatric units. Psychiatric Bulletin 27, 217-220.

Quirk A., Lelliott P. \& Seale C. (in press). The permeable institution: an ethnographic study of three acute psychiatric wards in London. Social Science and Medicine.

Rose D. (2000). Users' Voices. The Sainsbury Centre for Mental Health: London.

Rethink (2004). Behind Closed Doors: Acute Mental Health Care in the $U K$. Rethink: London. Retrieved February 23, 2006, from http://www.rethink,org/research/pdfs/Behind-Closed-DoorsReport.pdf.

Royal College of Psychiatrists Research and Training Unit (2006). Acute Psychiatric Ward Accreditation Service: Service Standards. Retrieved February 23, 2006, from http://www.rcpsych.ac.uk/ cru/qual.htm.

Sainsbury Centre for Mental Health (2005). Acute Care 2004: a National Survey of Adult Psychiatric Wards in England. Sainsbury Centre for Mental Health: London. 